\title{
Investigating the tension load of rubber composites by impact dynamic testing
}

\author{
L AMBRIŠKO ${ }^{1, *}$, D MARASOVÁ ${ }^{1}$ and M CEHLÁR ${ }^{2}$ \\ ${ }^{1}$ Faculty of Mining, Ecology, Process Control and Geotechnology, Technical University of Košice, Institute of Logistics, \\ Park Komenského 14, 04384 Košice, Slovak Republic \\ ${ }^{2}$ Faculty of Mining, Ecology, Process Control and Geotechnology, Technical University of Košice, Institute of Earth \\ Resources, Park Komenského 19, 04384 Košice, Slovak Republic
}

MS received 17 March 2016; accepted 7 July 2016

\begin{abstract}
This work deals with establishing the tension load by impact dynamic testing of rubber composite conveyor belts. The value of tension load affects the shape of the used impactor and use of a support system as well as the weight of the ram and the impact height. An increase in the allowable stress when the belt is tensioned was examined during the test, to determine the effect of impact on the tension load. The obtained values of tension load are assessed using basic mathematical and statistical methods. Using the Design of Experiments method, factors that significantly affect the value of the tension load are identified.
\end{abstract}

Keywords. Rubber conveyor belt; tension; DOE method; regression models.

\section{Introduction}

Large-scale continuous material transport (belt conveyor system) is encouraged to move large volume rapidly and due to high efficiency of continuous transportation compared with the discrete transport (by trains or trucks) [1,2]. Conveyor belts (CBs) are used in practically every industry where large quantities of goods are moved [3]; they are widely used to transport granular matter in bulk [4]. The CB transport systems have taken on a new significance in recent years. The application of new developed solutions leads to considerable reduction in operational costs of transport systems, while ensuring their high reliability and service life [5]. The belt itself can make up to $70 \%$ of the total costs of a transport system (calculated as cost per lifetime) [6].

CBs can be loaded with hundreds of tons of goods every hour, depending on the application, which causes elastic, as well as plastic, deformation of the material and, over time, wear. Impact loading is an important process in the transport industry as it causes wear and failure of critical components [3]. In the beginning the belt damages are not visible on their external surface. Only after uncovering the belt core it is possible to find the presence of cord or textile core damages, detachments and fractures [7].

A belt conveyor as a composite consists of several materials. Fabric CBs usually consist of a wear-resistant rubber top layer ('top cover'), a fabric carcass which provide tensile strength, skim layers for adhesion between rubber and carcass and a rubber bottom layer ('bottom cover') to cover the

*Author for correspondence (lubomir.ambrisko@tuke.sk) carcass and provide sufficient friction to the drive pulley [19]. The mechanical properties of matrices are greatly improved by incorporation of isora fibre. The composite product, where this fibre is used as a potential reinforcement in polyesters, will be a cost-effective and value-added material for various components of machines like CBs [20].

CBs of special importance, which must have high mechanical properties, have in their structure different insertions (textile, metallic) and their properties are based on adhesions rubber insertion [8]. These CBs are used for equipping large capacity conveyors or those working under heavy conditions (sharp slope and high speed, with big lengths to transport), which need a very good breaking strength, special flexibility and high reliability [9]. Rubber industry often faces the problem of wear of rubber parts. The wear of CBs is characterized by abrasion [10]. The description of the wear process for very heavily strained rubber products, for instance CBs for stone transport, is very essential. Sharp edges of stones and terrain roughness gradually cut (chip) off rubber parts. This wear considerably damages separate parts of the product and destroy it [11].

The primary mechanical function of the belt is to bear the transported bulk material during conveyance [12]. In order to stop the CB sagging between the support rollers it must be kept under tension [13], while the axial load in the belt corresponds to $1 / 10$ of the belt tensile strength. The critical energy that the belt is able to absorb by the deformation work is proportional to the belt tensile strength [14]. The value of critical energy depends, among other things, on the head shape, method of belt support, strength of belt tension, head weight and height of its fall [7]. The determination of the stress 


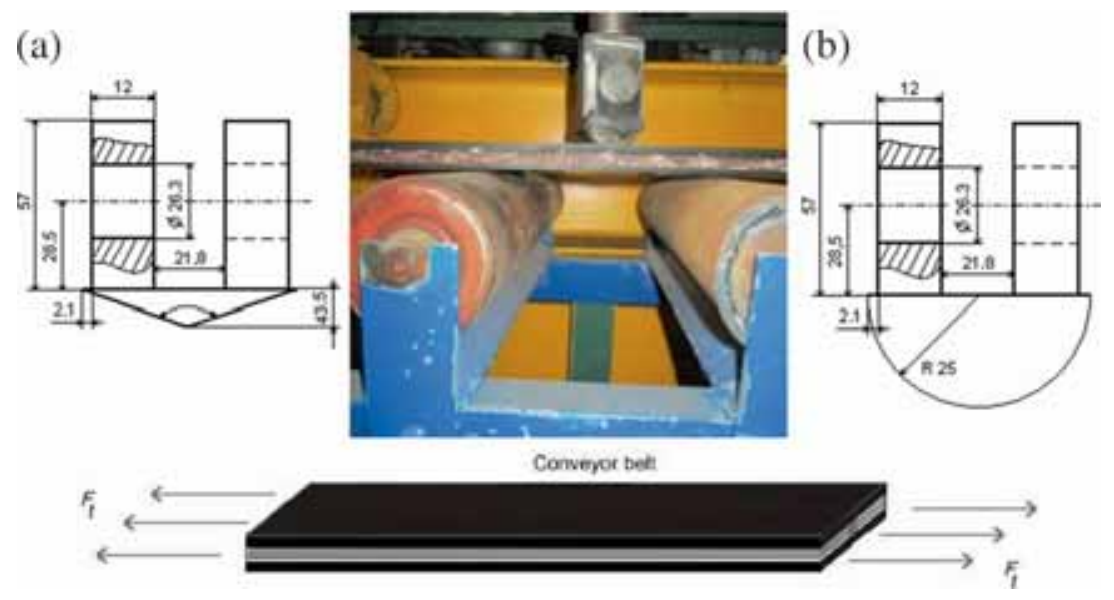

Figure 1. Tensioned CB with a support system and impactor; (a) pyramid and (b) sphere.

profile on the belt induced by bulk material is essential; it is critical for the engineering design of the $\mathrm{CB}$ with required strength and proper tension [15]. In Liu et al [12] the pressure distribution caused by bulk material on a loaded $\mathrm{CB}$ was determined using theoretical and experimental approaches. The determination of the pressure distribution is also important for the engineering design of belts and the analysis of the belt-bulk material interaction. The theoretical analysis of the pressure distribution caused by the bulk material on a loaded CB is complicated due to cyclic active and passive stress states in the bulk material [16].

The objective of the article is the analysis of increase in the allowable stress caused by the dynamic force in the $\mathrm{CB}$, which is developed in real conditions at the material's impact on the belt, particularly on the chutes, and causes the damage thereto.

\section{Materials and methods}

For experiments, CBs of type P 2000/4, $8+4$ were used. They are rubber belts with a 4-component textile-polyamide skeleton, with the strength of $2000 \mathrm{~N} \mathrm{~mm}^{-1}$. Experiments were realized on test equipment that is available at the Institute of Logistics on Technical University of Košice. Test samples with dimensions of $150 \times 1200 \mathrm{~mm}^{2}$ were attached at both ends to hydraulic grips and tensioned with load of $30 \mathrm{kN}$, which corresponds to $1 / 10$ of the belt tensile strength. Ram weight is $50 \mathrm{~kg}$ and for individual measurements it can vary in the range of $50-100 \mathrm{~kg}$ with an increase of $10 \mathrm{~kg}$. The impact height can be gradually increased from $0.2 \mathrm{~m}$ to a maximum of $2.6 \mathrm{~m}$. The tests can be carried out with a support system (figure 1) with pyramid or sphere impactor (figure 1). In the tests without the supporting system, in other words without steel idler rolls, only pyramid impactor was used.

Using the Design of Experiments (DOE) method [17,18] the effects of factors and their interactions that greatly affect the value of the tension load $\left(F_{t}\right)$ and operate at 1 st ram impact on $\mathrm{CB}$ were identified.
Table 1. List of input factors and their levels.

\begin{tabular}{llcc}
\hline & \multicolumn{1}{c}{ Factors } & Low level -1 & High level +1 \\
\hline A & Ram weight $(\mathrm{kg})$ & 50 & 80 \\
B & Impact height (m) & 0.4 & 1.4 \\
C & Head type (-) & Sphere & Pyramid \\
\hline
\end{tabular}

\section{Results}

\subsection{Design and evaluation of experiment}

The proposed experiment was focused on the monitoring of the effect of three factors (table 1): ram weight (factor A), impact height (factor B) and head type (factor C). The objective is to determine which of the factors or their interactions significantly affect the response, i.e., the value of the tension load $F_{t}(\mathrm{kN})$ exerted when the ram falls on the CB. The tests were carried out with a support system both with pyramid and sphere impactors with the distance of the longitudinal axes of the rollers being $200 \mathrm{~mm}$. During the experiments the CB breakdown did not occur.

A scheme of full three-factor experiment with two levels without repetitions, including the interactions, was created, whereas the number of all possible experimental runs was again $2^{3}$, i.e., 8 experimental runs. Graphical representation of the experiment using a cube is shown in figure 2, where the cube corners contain the response values.

Graphical representation of the main effects of all factors is shown in figure 3. The analysis indicates that the most intensive tension load exerted as the ram impacts the $\mathrm{CB}$ is reached when the first two factors (excluding factor $\mathrm{C}$ ) are set on the high level.

Table 2 clearly indicates that the strongest effect on the monitored response is by factor B (impact height) and factor A (ram weight). Negligible effect was observed for factor C (head type). Significance of individual effects of factors or interactions is tested using the $t$-test and by the $p$-value determination. The analysis indicates that only the main factors 


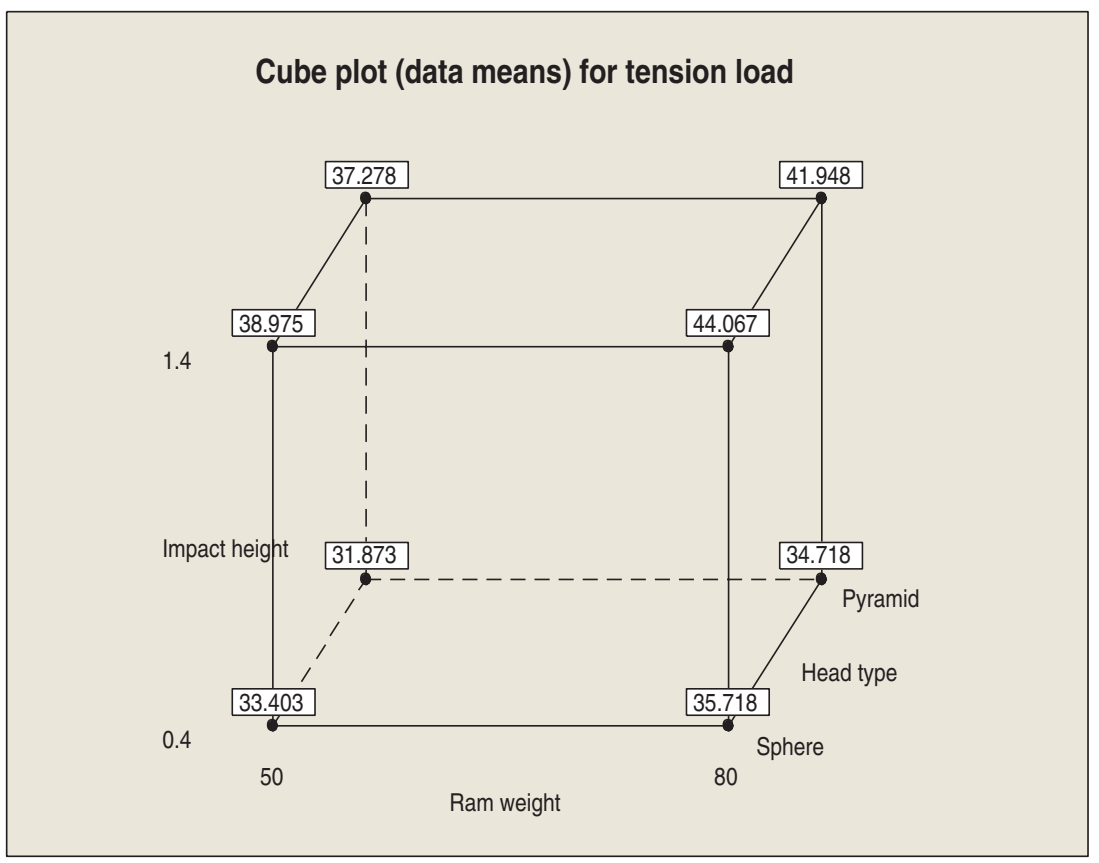

Figure 2. Graphical representation using a cube plot.

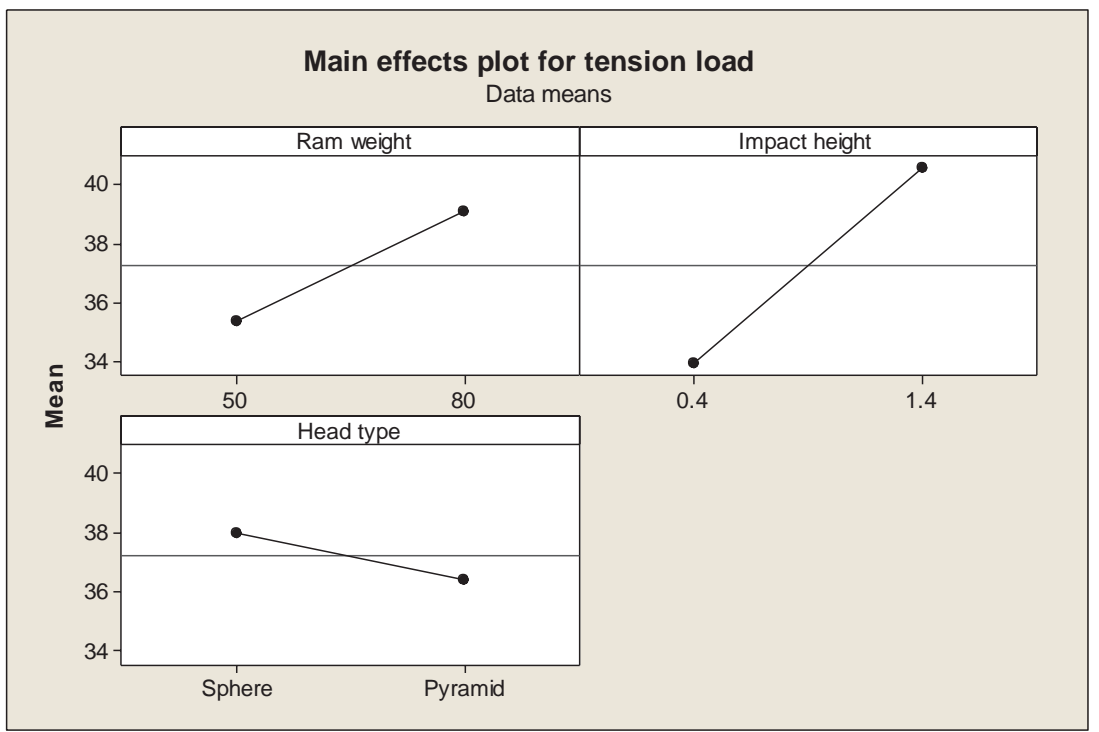

Figure 3. Graphical representation of main effects.

Table 2. The main effects of factors.

\begin{tabular}{lccc}
\hline & Factor A & Factor B & Factor C \\
\hline Effect of factors & 3.73 & 6.64 & -1.59 \\
\hline
\end{tabular}

A and B have a statistically significant effect on the output value of the tension load.

Significance of the effects can be assessed graphically; this type of assessment of the significance of effects and their interactions is most frequently made using the Pareto chart (figure 4) and the normal probability plot (figure 5). The Pareto chart (figure 4) reveals which factors and interactions have statistically significant relationship with the tension load on the significance level of $\alpha=0.05$.

Factors and interactions that do not have any influence are located near the drawn line (figure 5). Factors and interactions located out of the drawn line are regarded as significant. The plots (figures 4 and 5) indicate that the statistically significant effect on the response is present only for the impact height (factor B) and ram weight (factor A). 


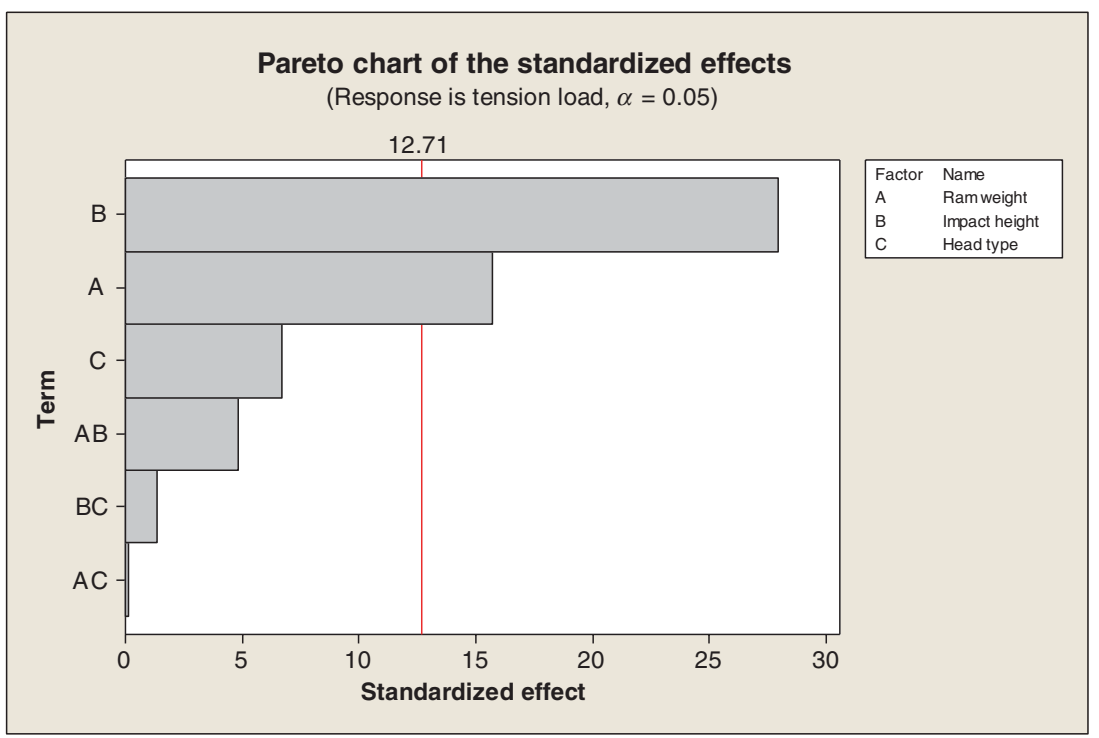

Figure 4. The Pareto chart of the significance of factors and interactions.

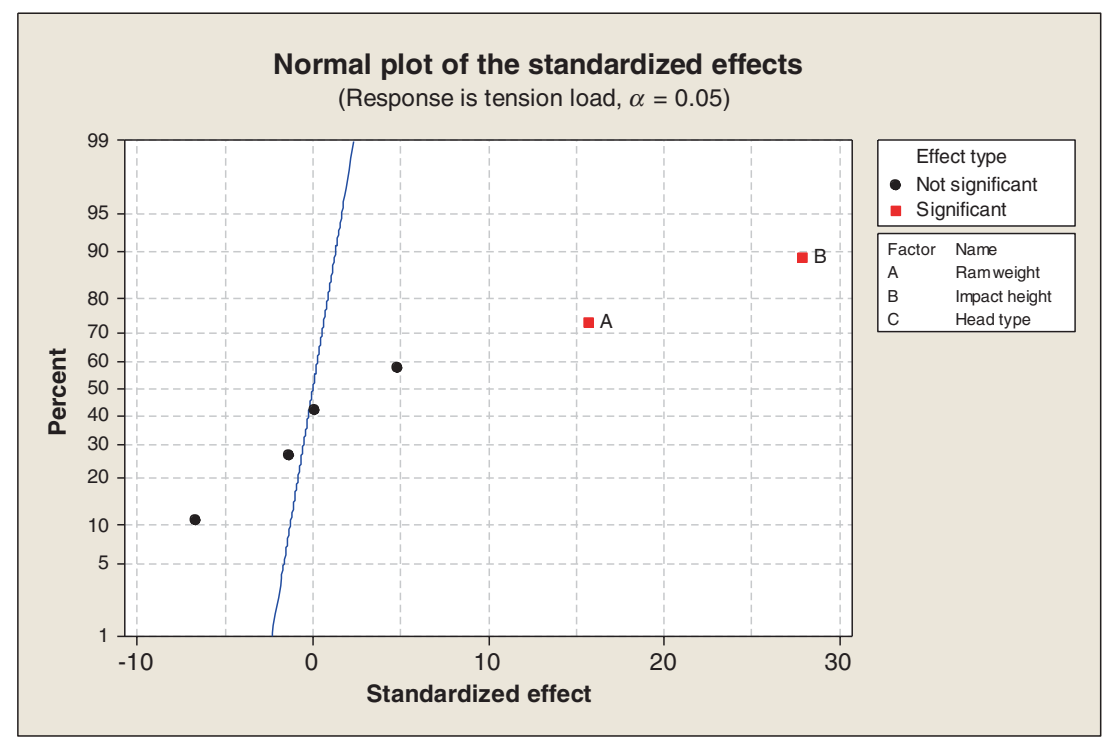

Figure 5. Normal probability plot of the significance of factors and interactions.

The interaction plots (figure 6) facilitate the identification of important interactions between the factors. If the shown lines are parallel, the interaction between the factors does not exist or is insignificant. The larger the angle between the lines, the stronger the interaction between the monitored factors. Between the factors A and B, B and C and between A and $\mathrm{C}$ significant interaction does not exist.

The model of a full three-factor experiment containing the main factors and all two-factor interactions is determined by [18]

$$
y=\beta_{0}+\beta_{1} x_{1}+\beta_{2} x_{2}+\beta_{3} x_{3}+\beta_{12} x_{1} x_{2}+\beta_{13} x_{1} x_{3}+\beta_{23} x_{2} x_{3},
$$

where $y$ is the response, $x_{1}-x_{3}$ represent values of factors, their product represents interactions between the respective two factors (e.g., $x_{1} x_{2}$ represents the $\mathrm{AB}$ interaction) and the $\beta \mathrm{s}$ are estimates of the regression model coefficients that can also be calculated using the effects. The values of all model coefficients are shown in table 3.

The value of the determination coefficient $R_{\text {adj }}^{2}=99.36 \%$ indicates that the identified regression model explains the experimental results up to $99 \%$.

Using contour plots (figure 7) helps to visualize the response surface. Plots are useful for establishing desirable response values and operating conditions. These plots show how a response variable relates to two factors (weight and height) based on a model equation. 


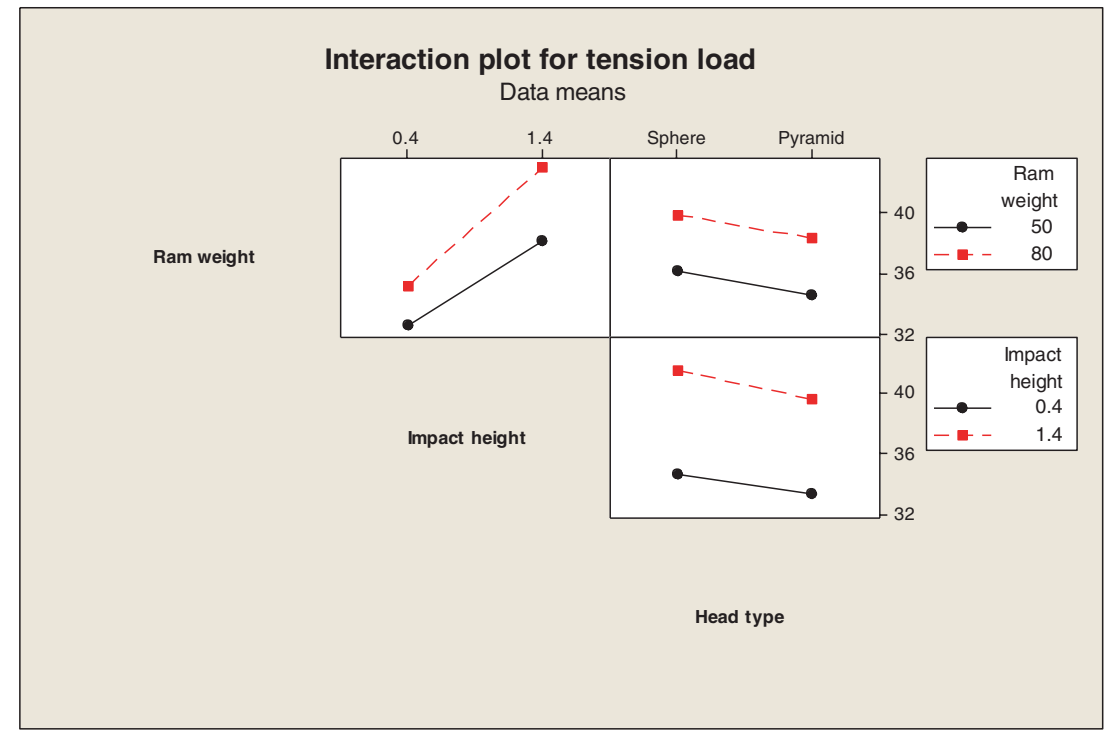

Figure 6. Interaction plot of main effects.

Table 3. The coefficients point estimate of the regression model.

\begin{tabular}{lrcccccr}
\hline Coefficient & $\beta_{0}$ & $\beta_{1}$ & $\beta_{2}$ & $\beta_{3}$ & $\beta_{12}$ & $\beta_{13}$ & \multicolumn{1}{c}{$\beta_{23}$} \\
\hline Value & 37.248 & 1.865 & 3.320 & -0.793 & 0.575 & 0.014 & -0.161 \\
$p$-Value & 0.002 & 0.041 & 0.023 & 0.095 & 0.130 & 0.928 & 0.406 \\
\hline
\end{tabular}

Because plots show only two factors at a time, any other factor (head type) is held at a constant level. Thus, plots are valid only for fixed levels. If holding levels are changed, the response surface also changes (figure 7). Therefore, it makes sense to hold head type fixed at its low and high levels and compare the plots. Points of a contour plots that have the same response are connected to produce contour lines of constant responses. The darkest green (i.e., grey) area indicates the contour where the response is the highest. The maximum tension load of $44 \mathrm{kN}$ is reached with the ram weight $=80 \mathrm{~kg}$, the impact height $=1.4 \mathrm{~m}$ and spherical impactor. It can be concluded, on the basis of following visualization of values of the monitored response, that higher tension loads were measured in the case of the spherical impactor.

\subsection{Analysis of the impact to the tension load}

Tension load, during impact $\mathrm{CB}$ testing, reaches the maximum value at 1 st ram impact on $\mathrm{CB}$. This value depends on several factors. It affects the shape of the used impactor, use of a support system and the CB strength as well as the weight of the ram and the impact height. An increase in the allowable stress was examined, when the belt is tensioned during the test, to determine the effect of impact on the tension load. On the basis of the relation

$$
F_{t i}=\frac{F_{t}-F_{t 0}}{F_{t 0}} \times 100 \%,
$$

where $F_{t i}$ is percentage increase of tension load, $F_{t}$ is tension load that operates at $1 \mathrm{st}$ ram impact on $\mathrm{CB}$ and $F_{t 0}$ is tension load of $30 \mathrm{kN}$ ( $1 / 10$ of the strength of investigated CB), plots shown in figures 8 and 9 were obtained.

Tension load of the belt increases during impact testing. It was found, in examining the effect of the support system, that in the case of its omitting the tension load very significantly increases (figure 9). The increase in the value of the tension load of $50 \%$ is by a maximum weight of the ram $(100 \mathrm{~kg})$ and a maximum impact height $(1.4 \mathrm{~m})$ using the support system, whereas by its omitting it increased to $110 \%$. DOE method (design of another experiment) confirmed significant effects on response of the impact height (factor B), a supporting system (factor $\mathrm{C}$ ) and the $\mathrm{BC}$ interaction.

Type of the impactor causes, in a smaller scale, the tension load to increase (figure 8). In the case of impactor influence on increase of the tension load, greater increases were found for the spherical impactor. A rise in the weight of the ram clearly showed lesser differences between the increases in the tension load for sphere and pyramid. The DOE method confirmed the expected effect of two fundamental factors, namely impact height and ram weight at the tension load (see Section 3.1). The head type, in comparison with impact height and ram weight, had negligible effect, which was detected for all two-factor interactions too.

3.2a Creation of regression models: The obtained values of tension load that operate at the 1st ram impact on CB are assessed using basic mathematical and statistical methods. Estimates of coefficients of the searched regression models are made using the regression analysis. Measured values were used to produce several relations with a better 


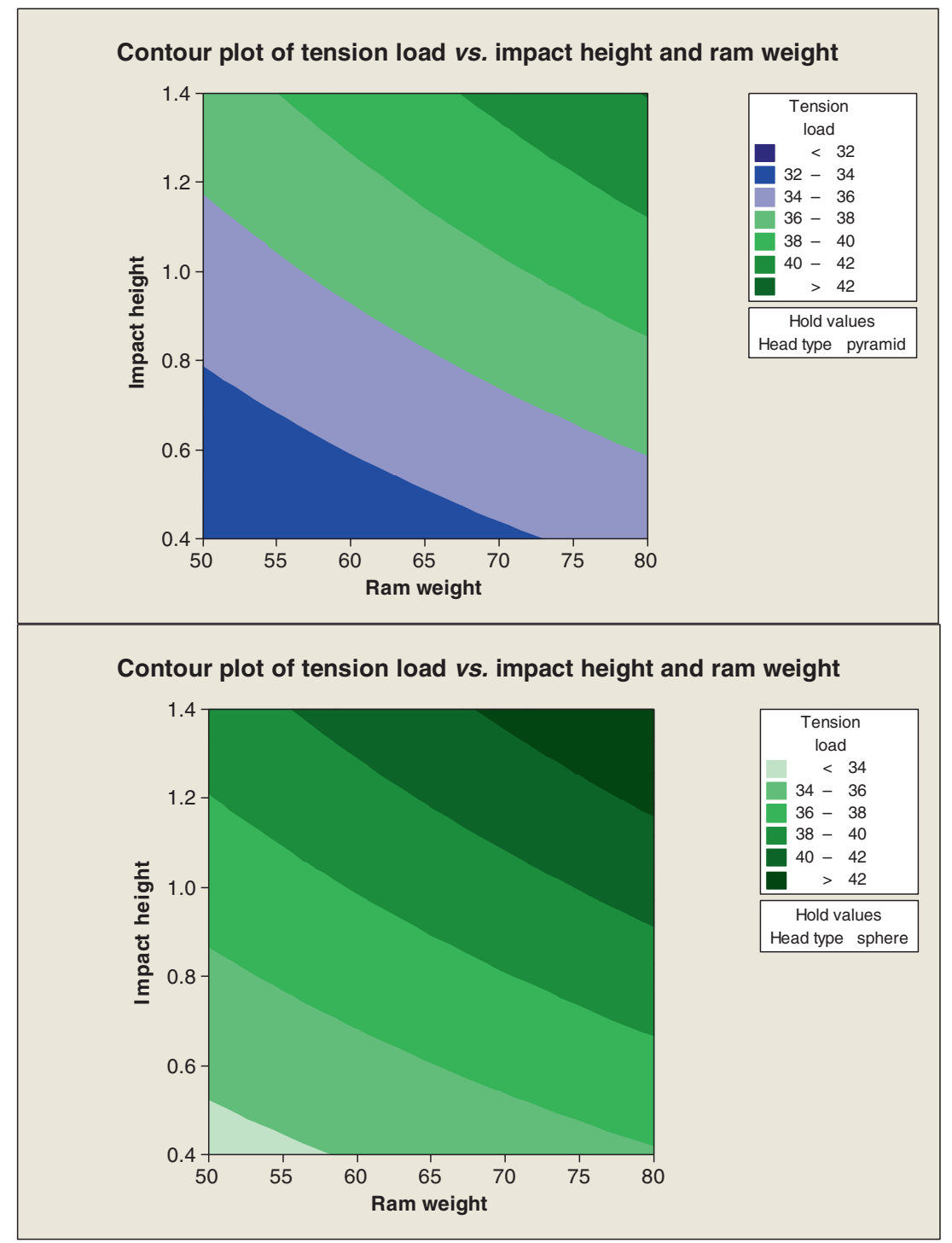

Figure 7. Contour plots.

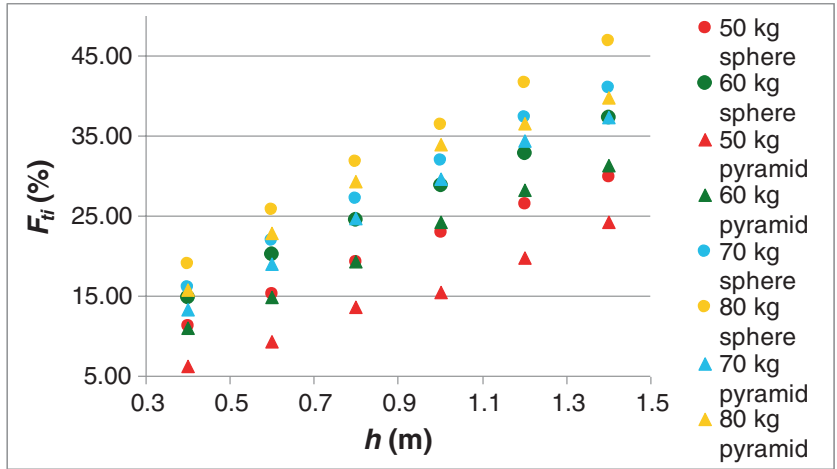

Figure 8. The influence of the impactor on the increase of tension $\operatorname{load} F_{t i}$.

predicative ability with regard to results. The relations that are valid for both support system (table 4) and type of used impactor (tables 5 and 6 ) can be described by models with

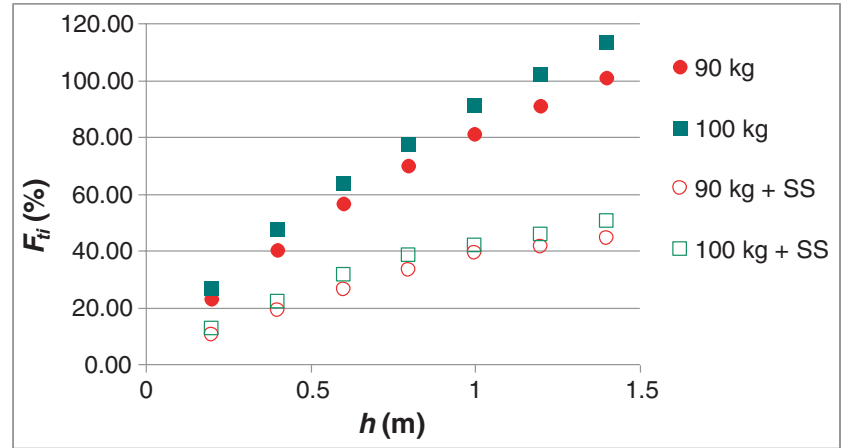

Figure 9. The influence of the support system on the increase of tension load $F_{t i}$.

point estimates. Monitored relations $F_{t}=f(h)$ can be described by a polynomial function of the second degree, which is the most suitable model. 
Table 4. Regression models of the dependence between the tension load $F_{t}$ and height $h$ valid for a given weight $m$ from the perspective of support system (SS; - , without; + , with).

\begin{tabular}{lll}
\hline$m(\mathrm{~kg})$ & \multicolumn{1}{c}{ Regression model } & \multicolumn{1}{c}{$R^{2}$} \\
\hline $90-\mathrm{SS}$ & $F_{t}=31.238+29.728 h-6.5661 h^{2}$ & 0.9997 \\
$90+\mathrm{SS}$ & $F_{t}=29.864+16.711 h-5.1071 h^{2}$ & 0.9979 \\
$100-\mathrm{SS}$ & $F_{t}=32.076+32.136 h-6.8042 h^{2}$ & 0.9993 \\
$100+\mathrm{SS}$ & $F_{t}=30.473+17.777 h-5.3964 h^{2}$ & 0.996 \\
\hline
\end{tabular}

Table 5. Regression models of the dependence between the tension load $F_{t}$ and height $h$ valid for a given weight $m$ from the perspective of spherical impactor.

\begin{tabular}{lll}
\hline$m(\mathrm{~kg})$ & Regression model & $R^{2}$ \\
\hline 50 & $F_{t}=30.788+6.758 h-0.6487 h^{2}$ & 0.9999 \\
60 & $F_{t}=31.416+8.08 h-0.8049 h^{2}$ & 0.9993 \\
70 & $F_{t}=31.05+9.9729 h-1.3433 h^{2}$ & 0.9995 \\
80 & $F_{t}=31.704+10.811 h-1.45 h^{2}$ & 0.9987 \\
\hline
\end{tabular}

Table 6. Regression models of the dependence between the tension load $F_{t}$ and height $h$ valid for a given weight $m$ from the perspective of pyramid impactor.

\begin{tabular}{lcc}
\hline$m(\mathrm{~kg})$ & Regression model & $R^{2}$ \\
\hline 50 & $F_{t}=30.295+3.7215 h+0.8638 h^{2}$ & 0.9927 \\
60 & $F_{t}=30.36+7.3993 h-0.6129 h^{2}$ & 0.9972 \\
70 & $F_{t}=29.78+11.358 h-2.2384 h^{2}$ & 0.9992 \\
80 & $F_{t}=29.253+15.552 h-4.6799 h^{2}$ & 0.9981 \\
\hline
\end{tabular}

\section{Conclusions}

The tension stress of the $\mathrm{CB}$ has an important role during the operation. Significant effect of the dynamic load to the CB occurs in the chute of transported material. Thereby, in long-run operation, the belt may break down, i.e., the loss of belt functionality. The construction of the belt leads to irreversible changes-damage of belt structural components occurs. As a consequence of chute, the allowable stress of belt is considerably increased. Several factors affect the stress increase: the shape of the used impactor and use of a support system as well as the weight of the ram and the impact height. Analysis of their interactions with the $\mathrm{CB}$, including the obtained regression models, is important not only in terms of conveyor design but also for predicting the stress profile on a loaded belt.

\section{Acknowledgement}

This article is the result of the implementation of the Project: University Science Park TECHNICOM for Innovation Applications Supported by Knowledge Technology, ITMS: 26220220182, supported by the Research and Development Operational Programme funded by the ERDF. 'We support research activities in Slovakia/This project is being co-financed by the European Union.'

\section{References}

[1] Pang Y and Lodewijks G 2012 Proceedings of 9th IEEE international conference on networking, sensing and control $\mathrm{p} 79$

[2] Zeng F, Wu Q, Chu X and Yue Z 2015 Measurement 75230

[3] Molnar W, Nugent S, Lindroos M, Apostol M and Varga M 2015 Polym. Test. 421

[4] Cordero M J and Pugnaloni L A 2015 Powder Technol. 272290

[5] Mazurkiewicz D 2015 Arch. Civ. Mech. Eng. 15412

[6] Hartlieb R and Wallthor V 1975 Berg-Hüttenmann Monatsh. 120371

[7] Komander H, Hardygóra M, Bajda M, Komander G and Lewandowicz P 2014 Eksploat. Niezawodn.-Maint. Reliab. 16579

[8] Dobrotă D 2015 Procedia Eng. 1001160

[9] Amza G, Dobrotă D, Semenescu A and Iancului D 2008 Mater. Plast. 45377

[10] Manas D, Stanek M, Manas M, Ovsik M, Pata V and Cerny J 2011 Proceedings of the 22nd international DAAAM symposium $\mathrm{p} 415$

[11] Cerny J, Kyas K, Krumal M, Martin M, Manas D, Manas M and Michal M 2010 Proceedings of the 21st international DAAAM symposium $\mathrm{p} 1189$

[12] Liu X, Pang Y and Lodewijks G 2016 Measurement 77307

[13] Jones D R H 1995 Eng. Failure Anal. 259

[14] Antoniak J 2010 Belt conveyors in underground mining and quarrying energy (in Polish) (Gliwice: Wydawnictwo Politechniki Ślảskiej)

[15] Liu X, Pang Y and Lodewijks G 2015 Powder Technol. 273102

[16] Spaans C 1991 Bulk Solids Handl. 11809

[17] Miller I 2010 DOE: design and analysis of an experiment using MINITAB® (in Czech) (Praha: Interquality)

[18] Montgomery D C 2002 Design and analysis of experiments (New York: John Wiley)

[19] Röthemeyer F and Sommer F 2006 Kautschuk technologie (München Wien: Carl Hanser Verlag)

[20] Lovely M, Joseph K U and Rani J 2006 Bull. Mater. Sci. 2991 